AGRICULTURE AND BIOLOGY JOURNAL OF NORTH AMERICA

ISSN Print: 2151-7517, ISSN Online: 2151-7525, doi:10.5251/abjna.2011.2.10.1336.1339

(C) 2011, ScienceHuß, http://www.scihub.org/ABJNA

\title{
Cultivation of oyster mushroom (Pleurotus pulmonarius) on amended corncob substrate
}

\author{
${ }^{1}$ Stanley H.O, ${ }^{1}$ Umolo, E.A and ${ }^{2}$ Stanley, C.N. \\ ${ }^{1}$ Department of Microbiology, University of Port Harcourt, Rivers State, Nigeria. \\ ${ }^{2}$ Department of Pharmaceutical Microbiology, University of Port Harcourt, Rivers State, \\ Nigeria. \\ CORRESPONDING AUTHOR \\ Department of Microbiology, University of Port Harcourt, Rivers State, Nigeria. \\ E-mail: okehstanley@yahoo.com \\ Phone: +234-8035431710
}

\begin{abstract}
This study evaluated the effect of supplementing corn cob substrate with rice bran on yield of Pleurotus pulmonarius ( $\mathrm{Fr}$ ) Quel. Un-supplemented corn cob ( $0 \%$ supplementation) gave the best yield in terms of the mean diameter of pileus $5.50 \mathrm{~cm}$, mean fresh weight of fruiting bodies $53.2 \mathrm{~g}$, mean height of stipe $3.64 \mathrm{~cm}$ and number of healthy fruiting bodies as 12 . The least yield was recorded with $30 \%$ supplementation as follows: mean diameter $3.20 \mathrm{~cm}$, mean fresh weight of fruiting bodies $30.0 \mathrm{~g}$, mean height of stipe $1.65 \mathrm{~cm}$ and number of healthy fruiting bodies as 5 .in terms of quantity and quality, the un-supplemented substrate produced better edible mushrooms.
\end{abstract}

Keywords: Edible mushroom, cultivation, supplementation, corn cob, rice bran and fruiting bodies.

\section{INTRODUCTION}

Mushrooms are non-timber forest products which are often found as saprophytes on soil, open fields, farm lands wood and roadsides. The fruiting bodies are large enough to be visible to the naked eyes. They belong to the class Basidiomycetes, order; Agaricales. Mushrooms are increasingly becoming popular as protein-rich delicious vegetable. Mushroom provides a variety of tastes, flavor and texture. Pleurotus species are characterized by a white spore pint attached to decurrent gills, often with an eccentric (off center) stipe, or no stipe at all. They always grow on wood in nature, usually on dead standing trees or on fallen logs. The common name "oyster mushroom" comes from the white shell-like appearance of the fruiting body. Reported nutrient composition is protein(25-50\%), fat $(2-5 \%)$, sugars $(17-47 \%)$, mycocellulose $(7-38 \%), \quad$ and minerals(8-12\%). (Miles and Chang, 1997). Mushrooms contain vitamins such as niacin, riboflavin, vitamin $\mathrm{D}, \mathrm{C}, \mathrm{B}_{1}, \mathrm{~B}_{5}$ and $\mathrm{B}_{6}$. (Miles and Chang, 1997).

Mushroom cultivation is a useful method of environmental waste management and waste disposal. Many agricultural and industrial by-products can find uses in mushroom production.(Chinda, and Chinda (2007). Some of these materials litter and sometimes pollute our environment.

Waste land and waste materials are useful in the cultivation of mushrooms. The media (substrate) for mushroom production include rice straw, rice bran, wheat straw, pulp, corncobs, cocoa shell wastes, cotton seed bulb, cotton wastes from textile industry, brewers grain, saw dust (a big waste in timber industry), maize husks and cassava peelings.

The aim of this study therefore, is to encourage mushroom cultivation as a means of providing cheap and safe food resource.

Pleurotus species are good candidates for cultivation in Nigeria because of the following reasons:

- Some are efficient degraders of lignocellulosic materials.

- Some are easy to grow with simple technology.

- Some grow fast and can complete a full cycle in 3-4 weeks.

- The raw materials are abundantly available in Nigeria. 
Agric. Biol. J. N. Am., 2011, 2(10): 1336-1339

The commercial production of edible mushrooms should be encouraged in Nigeria, considering its potential contribution to the agricultural production, research, pollution control, waste management, medicine, economy, poverty alleviation and its potentials as cheap protein source.

\section{MATERIALS AND METHODS}

The spawn of Pleurotus pulmonarius used for this work was supplied by Chief M.M. Chinda of Diplomat Farms and Services Limited, Rivers State University of Science and Technology, Port Harcourt. Organic wastes used for the experimental work were obtained as follows:

Corncob (zea mays) were obtained from waste disposals along the East-West Road, Choba axis, Port Harcourt, Nigeria, whereas, the rice bran used for substrate supplementation were obtained from Diplomat Farms and Services Limited, Rivers State University of Science and Technology, Port Harcourt. Each substrate was replicated three times

\section{PREPARATION OF SUBSTRATES FOR CULTIVATION}

The dry corncob was chopped up into small pieces of about $2-4 \mathrm{~cm}$ long. $250 \mathrm{~g}$ of dry corncob was weighed out and soaked overnight in $750 \mathrm{ml}$ of water in each experimental vessel, a 4 liter transparent white polypropylene bucket, which were uniformly perforated from the mid-point to the upper part of the bucket.

On the next day, the corncob had absorbed the water. The rice bran was crushed into flour, weighed out and added to the wet corncob in various proportion as to derive different percentages of corncob and rice bran for different treatments

1. $100 \%$ corncob $=T_{0}$ (un-supplemented corncob).

2. $90 \%$ corncob $+10 \%$ rice bran $=T_{1} \quad(10 \%$ supplementation)

3. $80 \%$ corncob $+20 \%$ rice bran $=\mathrm{T}_{2} \quad(20 \%$ supplementation)

4. $70 \%$ corncob $+30 \%$ rice bran $=\mathrm{T}_{3} \quad(30 \%$ supplementation)

The substrate materials were mixed thoroughly, pressed down, covered and then pasteurized at $70^{\circ} \mathrm{C}$ for one hour. After cooling, inoculation was done with grain spawn of $12.5 \mathrm{~g}$ in each experimental bucket, that is $5 \%$ spawn. The spawn was then mixed with the various levels of substrates supplementation contained in the buckets, which was pressed down and covered. The covering was necessary to reduce contamination, minimize the escape of water vapour and also to trap carbon dioxide, which helps to stimulate vegetative growth (Zadrazil, 1978.) The doors and the windows of the growth room were shut and the floor was watered once everyday from the day of inoculation, to maintain the humidity of the room. After 6 days, the buckets were opened to increase the circulation of air. The windows were opened at intervals to increase ventilation.

Data collection: The yield of Pleurotus pulmonarius on the different levels of substrate supplementation (see plates 1-4) determined by recording the number, weight and size of the fruit bodies after sprouting. The measurements from the various replicates were added and their mean value calculated.

The following parameters of growth / yield were measured.

Number of fruit bodies: This was done by directly counting the number of fruit bodies on each substrate.

Height of fruit bodies: The height was measured in centimeters using transparent ruler from the base of the stipe to the pileus.

Diameter of the pileus: This was also measured in centimeters with ruler from one edge of the pileus across the stripe to the other edge.

Fresh weight of fruit bodies: This was done using an electrical weighting balance.

\section{RESULTS AND DISCUSSION}

Ten days after inoculation Whitish mycelia colonized the un-supplemented four days later (90h) fruit bodies appeared on the un-supplemented corn cob and 5 days (120h) after the appearance of mycelia growth, fruit bodies were observed on all the supplemented substrates.

Number of fruit bodies: The un-supplemented corncob produced the highest number of fruit bodies with a mean value of 12 . The next was 8 produced by $10 \%$ supplementation followed by $20 \%$ supplementation with 7 fruit bodies and the least 5 produced by $30 \%$ supplementation.

Height of stripe of fruit bodies: The fruit bodies produced on un-supplemented corncob had a mean height of $3.64 \mathrm{~cm}$ followed by $10 \%, 2 \%$ and $30 \%$ supplementation whose mean heights were $2.98 \mathrm{~cm}$, $1.83 \mathrm{~cm}$ and $1.65 \mathrm{~cm}$ respectively. 
Agric. Biol. J. N. Am., 2011, 2(10): 1336-1339

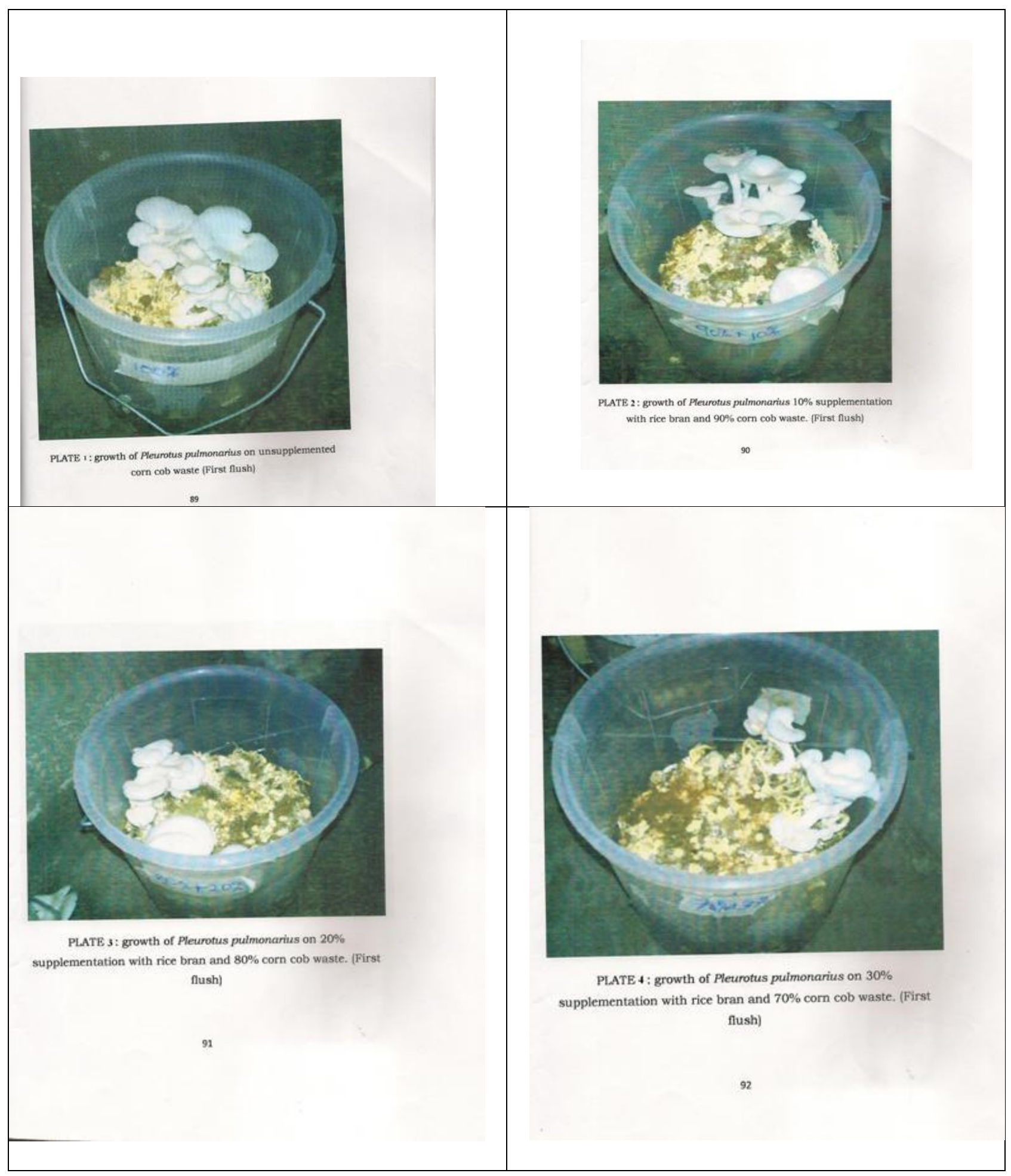


Diameter of the pileus: The fruit bodies produced on un-supplemented corncob had a mean value of $5.50 \mathrm{~cm}$ followed by $4.07 \mathrm{~cm}, 3.93 \mathrm{~cm}$ and 3.20 produced on $10 \%, 20 \%$ and $30 \%$ supplementation respectively.

Fresh weight of fruit bodies.: Mean fresh weight of fruit bodies produced on un-supplemented corncob was $53.2 \mathrm{~g}$ followed by $42.4 \mathrm{~g}, 40.0 \mathrm{~g}$ and $30.0 \mathrm{~g}$ produced on $10 \%, 20 \%$ and $30 \%$ supplementation respectively.

From all the parameters (number height of stripe, diameter pileus and fresh weight of fruit bodies) considered, the un-supplemented corncob proved to be the best substrate, for the cultivation of Pleurotus pulmonarius. The least yield of Pleurotus pulmonarius on all parameter considered were recorded on $30 \%$ supplementation $(70 \%$ corn cob + $30 \%$ rice bran).

Form the physicochemical analysis of the corncob used, it showed that, it had a total nitrogen value of $2.0 \mathrm{mg} / \mathrm{kg}$ and $6.44 \%$ of total organic carbon, whereas the rice bran had $2.4 \mathrm{mg} / \mathrm{kg}$ of total nitrogen. According to Chang and Buswell (1996), nutrient content of substrates affect the formation of fruit bodies.

Also Zadrazil (1980) stated that the growth of Pleurous species is favoured on substrates of low nitrogen content (ie high carbon to low nitrogen ratio is needed to raise on good yield). This simply explains the good yield of Pleurotus pulmonarius on un-supplemented corncob

\section{CONCLUSION}

The un-supplemented corncob produced better fruit bodies of Pleurotus pulmonarius than the various levels of substrate supplementation studied. More research work is encouraged to investigate the effect of substrate supplementation on sustained yield of edible mushrooms in various harvests with regards to commercial production.

\section{REFERENCES}

Chinda, M.M. and Chinda, F.(2007), Mushroom Cultivation for Health and Wealth.Apara Printers and Converters Limited, Lagos. P.23-87.

Chang, S.T. and Buswell, J.A. (1996), Mushroom Nutricentials, World Journal of Microbiology and Biotechnology, 12:473-476.

Miles, P.G. and Chang, S.T.(1997), Mushroom Biology, P.1-96. World Scientific Press, Hong Kong.

Zadrazil, F, (1978). Cultivation of Pleurotus. In: The Biology and Cultivation of Edible Mushroom Ed. Chang, S.T and Hayes, W.A. Academic Press, New York p 521554

Zadrazil, F. (1980), Influence of Ammonium Nitrate and Organic Supplements on The Yield of Pleurotus SajorCaju (Fries), Singer. European Journal of Appl. Microbial and Biotech 9:31-34 